\title{
Personal Wellbeing Index in a National Cohort of 87,134 Thai Adults
}

\author{
V. Yiengprugsawan $\cdot$ S. Seubsman $\cdot$ S. Khamman $・$ L. L.-Y. Lim • \\ A. C. Sleigh $\cdot$ the Thai Cohort Study Team
}

Accepted: 19 October 2009/Published online: 28 November 2009

(C) Springer Science+Business Media B.V. 2009

\begin{abstract}
Satisfaction with life correlates with other measures of subjective wellbeing and correlates predictably with individual characteristics and overall health. Social indicators and subjective wellbeing measures are necessary to evaluate a society and can be used to produce national indicators of happiness. This study therefore aims to help close the gap in wellbeing data for Thailand. The specific aims are to: (1) calculate the Thai PWI and domain scores using a large scale sample; (2) examine the level of life satisfaction of Thais when compared to international standards; (3) examine the Thai PWI and domains in relation to demographic, socioeconomic, and geographic characteristics. Our report derives from the findings on the Personal Wellbeing Index (PWI) in a large national cohort of Sukhothai Thammathirat Open University adult students living all over Thailand ( $n=87,134)$. This Thai cohort had an overall PWI of 70.0 on a scale from 0 to 100 which is consistent with Western populations. The 'spirituality and religion' domain had the highest average score. 'Standard of living', 'future security' and 'achievement in life' made the largest contribution to overall 'satisfaction in life as a whole'. These domains also show a positive trend with increasing age, being married, higher income, more education, more household assets, and rural residence. The PWI will be an important tool for policymakers to understand the subjective wellbeing of population groups especially as Thailand is undergoing a political and economic transition.
\end{abstract}

Keywords Subjective wellbeing $\cdot$ Personal wellbeing index $\cdot$ Life satisfaction · Open university cohort . Thailand

Thai Cohort Study Team Thailand: Jaruwan Chokhanapitak, Chaiyun Churewong, Suttanit Hounthasarn, Suwanee Khamman, Daoruang Pandee, Suttinan Pangsap, Tippawan Prapamontol, Janya Puengson, Yodyiam Sangrattanakul, Boonchai Somboonsook, Nintita Sripaiboonkej, Pathumvadee Somsamai, Duangkae Vilainerun, Wanee Wattanaphan.

Australia: Chris Bain, Cathy Banwell, Bruce Caldwell, Gordon Carmichael, Tarie Dellora, Jane Dixon, Sharon Friel, Matthew Kelly, Tord Kjellstrom, Tanya Mark, Anthony McMichael.

V. Yiengprugsawan $(\bowtie) \cdot$ S. Seubsman · S. Khamman · L. L.-Y. Lim ·

A. C. Sleigh - the Thai Cohort Study Team

National Centre for Epidemiology and Population Health, ANU College of Medicine, Biology \&

Environment, The Australian National University, Canberra, ACT 0200, Australia

e-mail: vasoontara.yieng@anu.edu.au; vasoontara.yieng@gmail.com 


\section{Introduction}

Earlier studies have shown that satisfaction with life correlates with other measures of subjective wellbeing, and correlates predictably with individual characteristics and overall health (Diener 1984; Diener et al. 1985; O'Dea et al. 1999; Siahpush et al. 2008). Social indicators and subjective wellbeing measures are necessary to evaluate a society and can be used to produce national indicators of happiness (Diener 2000). Subjective wellbeing can be measured directly instead of inferred from traditionally used objective indicators, such as economic development and income (Cummins 2000). Although many view economic productivity as the goal of development, some researchers challenge the existence of a link between income and wellbeing (Easterlin 2003; Eckersley 2002; Stevenson and Wolfers 2008). Others note that economic development itself may diminish traditional cultural values and social networks and hence the sense of wellbeing of individuals (Sen 1988, 1999).

One such measure of subjective wellbeing is the Personal Wellbeing Index (PWI) which has demonstrated good psychometric performance in terms of its reliability, validity and sensitivity. The PWI is an indicator of personal wellbeing that assesses level of life satisfaction as a whole as well as domains such as standard of living, achievement in life, personal health, personal relationship, personal safety, community-connectedness, and future security. Later work revealed that the importance of the spiritual domain (Cohen 2002) and an eighth domain cluster on spirituality and religion was recently added to the PWI (The International Wellbeing Group 2006).

The PWI is being used by over 100 researchers in 50 countries and has been translated into several languages. For western populations, the normative range has been found to be $70-80$ points on a $0-100$ scale distribution with a mean of 75 , as in Australia (Cummins et al. 2003) and Austria (Renn et al. 2009). Cross-cultural comparisons between Australia and Hong Kong found that the PWI in the former lay in the 70-80 range whereas in the latter scores fell between 65 and 75 (Lau et al. 2005). In Algeria, the PWI and domain scores were relatively low with a mean of 50 (Tiliouine et al. 2006).

Most studies of personal wellbeing are produced and applied in developed countries. There are relatively few studies for developing countries, even less in Asia. PWI values in Chinese samples are generally about 10 points lower than Western counterparts, partly due to a response bias caused by modesty in Chinese culture (Chen and Davey 2008). Based on a small sample in Tibet, PWI was close to 70, much higher than expected in a developing country (Webb 2008). The relative lack of wellbeing data for Asian countries is important. Such subjective indicators have the benefit of assessing appreciation of life as a whole and this is of great importance to policy makers mapping out development strategies (Veenhoven 2002).

This study aims to help close the gap in wellbeing data for Thailand. The specific aims are: (1) calculate the Thai PWI and domain scores using a large scale sample; (2) examine level of life satisfaction of Thais when compared to international standards; (3) examine Thai PWI and domains in relation to demographic, socioeconomic, and geographic characteristics.

\section{Thai Economy and Development}

Thailand is located in mainland Asia, bordered on the west and northwest by Myanmar, on the northeast and east by Laos and Cambodia. To the south lies the Gulf of Thailand, 
Malaysia and the Andaman Sea. Thailand is a country with a population of 67 million in the midst of rapid health and economic transitions. According to the United Nations Development Programme, the Human Development Index for Thailand is 0.781 (composite measure of life expectancy, adult literacy, and standard of living), which gives the country a rank of 78th out of 177 countries with data (UNDP 2005).

Thailand's annual population growth rate has declined significantly from $2.7 \%$ between 1960 and 1970 to $1.05 \%$ in 2000. With the exception of the economic crisis years (1997-98), rapid Gross Domestic Product (GDP) growth in Thailand has brought about sustained reduction in absolute poverty during the past few decades. The rate of reduction of poverty has been strongly related to the rate of growth of GDP. However, it has been noted in various studies that relative poverty (inequality in the income distribution) exists among regions in the country (Krongkaew 1993; Warr 2004) and to a certain extent between urban (municipal) and rural (non-municipal) areas (Sarntisart 2004). The Northeast region had the largest population (34.2\% of the total), followed by the Central region (23.3\%), the Northern region (18.8\%), the South (13.3\%) and Bangkok (10.4\%) (NSO 2006). Bangkok is the most economically developed area, with the North and Northeastern regions trailing behind.

Thailand has moved on from public health challenges of high maternal and infant mortality and poverty-related diseases to a new set of emerging health problems, including chronic diseases and injuries, as part of an epidemiological transitions (Seubsman et al. 2007; Sleigh et al. 2008). Improvements in life expectancy continued through the 1960s and beyond. By the mid-1970s, life expectancy was around 58 years for males and 65 years for females and by 2000 it has risen to almost 70 years for males and 75 years for females. In 2004, the World Health Report classified Thailand as having low child and low adult mortality (WHO 2004). Thailand has developed a strong and geographically distributed health care infrastructure over three decades of primary health care (Wibulpolprasert et al. 2008). In 2001, the Thai Government committed to improving health conditions for all Thai citizens by introducing universal health coverage (Tangcharoensathien and Jongudomsuk 2004). This was an important milestone for a middle-income country.

\section{Thai Conceptual Framework for Personal Wellbeing}

Traditional Thai values of family and community cushioned the economic crisis of 1997 and served as social safety nets that could be tapped during crises (World Bank 2000). Sufficiency economy is a Thai philosophy led by the King that stresses the (Buddhist) middle path at individual, family, and community levels. This philosophy focuses on balanced development which aims to reduce the vulnerability of the nation to inevitable shocks and excesses arising from globalization. Social reform gained momentum during the 9th (2002-2006) and the 10th (2007-2011) National Economic and Social Development Plan (NESDB) with many of the strategies revolving around human-centred knowledge and social development, growing social capital at the community level (Khamman 2008; NESDB 2005; Wasi 2004). Thailand has been influenced by leading public intellectuals responding to Buddhist development philosophy and the associated Bhutanese emphasis on Gross National Happiness rather than Gross National Product (Wasi 2004). Accordingly, the Thai National Economic Social and Development Board has defined happiness as a state of wellbeing, with quality of life well-balanced among physical, mental and intellectual attributes, and with good integration of the economy, society and the environment. An adaptation of the NESDB Thai 'Green and Happiness Index' conceptual framework is shown in Fig. 1 (NESDB 2007). 


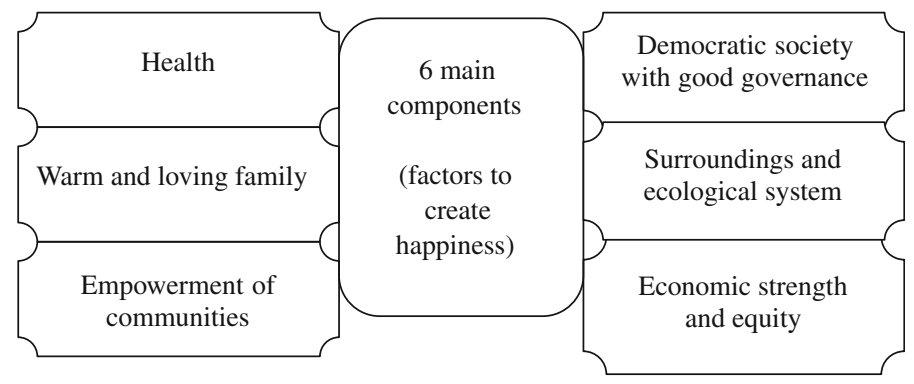

Source: NESDB 2007

Fig. 1 Conceptual framework of 'Green and Happiness Index' developed by the Thai National Economic and Board. Source: NESDB 2007

\section{Methodology}

\subsection{Study Design}

Data derive from a national cohort of 87,134 adult students from the Sukhothai Thammathirat Open University (STOU) who completed a baseline survey in 2005. STOU enrols distance-learning adult students residing all over Thailand, most of whom continue in their usual employment while studying part-time. The university accepts anyone who has completed high school or has completed junior high school and substantial work experience. For this report, only those aged 20 or above were included in the analysis resulting in 84,164 adult students.

The survey response rate was $44 \%$ which is high for a mail-out self-administered questionnaire; 54\% were females and the median age was 29 years. Individuals with missing data for given analyses were excluded meaning totals vary slightly according to the information available. In an earlier publication, the STOU cohort was compared with the general Thai population: the median ages were similar (29 years in 2005) but the cohort had more females (54.3 vs. $51.2 \%$ ), more urban residents (51.8 vs. $31.1 \%$ ), and relatively greater representation of Bangkok and Central area residents compared to Northeastern residents (Sleigh et al. 2008). Also, national population data for 2005 show that only $60 \%$ of Thais had completed primary education, whereas virtually $100 \%$ of the cohort had completed secondary education (NSO 2006). However, the cohort and general Thai population were quite similar for median monthly income (2,550 vs. 2,742 Baht in 2005 when 40 Baht $=$ US\$1) and for other socioeconomic indicators. So the cohort mainly includes Thais who are not better off than average and remain in their employment and live at home while studying at an open university.

The questionnaire covers a wide range of topics including demographic, socioeconomic and geographic information, health status, health- risk behaviours, health service use, social interaction and support, injuries, and family background. The test items were selfcompleted by the cohort members with no time limit. Questions were developed with collaboration between the Thai and the Australian teams with iterative back-translation to ensure the validity as the questionnaire was finalized in Thai.

The questionnaire contained information on individual and household characteristics. These include sex, age, martial status (married, single, separated/divorced/widowed), 
monthly income per month in Baht $(<7,000,7,001-10,000,10,001-20,000$, and $>20,000)$, education levels (junior/high school, diploma, bachelor degree/above), household assets (later categorized by total replacement value into three groups: low $<30,000$, middle 30,001-60,000, and high >60,000), and residence (Bangkok, urban not Bangkok, and rural). As well, we included a Thai translation of the standard eight personal wellbeing domain items (See Appendix) with responses for each item graded on a 10-point scale (The International Wellbeing Group 2006). Due to a very large size of the cohort most $P$-values are significant $(P<0.05)$ and many are highly significant $(P<0.001)$. For clarity of presentation $P$-values have not been reported and we focus on differences that are clearly substantial or interestingly small.

Informed written consent was obtained from all participants, and ethics approval was obtained from Sukhothai Thammathirat Open University Research and Development Institute (protocol 0522/10) and the Australian National University Human Research Ethics Committee (protocol 2004344).

\subsection{Data Analysis}

The PWI manual recommends that data be checked prior to analysis to ensure that there were no non-response records that could distort the results. After excluding such missing data for 2,050 respondents, 82,564 records were used for the main analysis. The standard PWI response scale was used, with numerical ratings ranging from 0 (extremely dissatisfied) to 10 (extremely satisfied). Data were then standardized into scores on a $0-100$ point distribution to allow a comparison to previous studies. This was done by shifting the decimal point one step to the right. E.g., a score of 7.0 became 70 points. Frequencies, means and standard deviations were calculated to describe respondents and items characteristics of the PWI.

All domain scores were aggregated and averaged to form PWI scores. The item 'Satisfaction with life as a whole' is not a component of the PWI. Hence, if it is used, it must be analysed as a separate variable. Bivariate correlations and multiple regression analyses were conducted to study the inter-relationships between the domains of the PWI as well as their contributions to 'satisfaction with life as a whole'.

\section{Results}

\subsection{Descriptive Statistics of the Cohort Members}

Table 1 presents descriptive data regarding the cohort members. There were more females $(54.7 \%)$ than males $(45.3 \%)$. Over $80 \%$ aged between 20 and 39 years and only $2.5 \%$ were over 50 years. Slightly more than half of cohort members were single, $41.6 \%$ were married, and $4.1 \%$ were separated, divorced or widowed. Socioeconomic data show that $41.9 \%$ of the cohort earned less than 7,000 Baht/month, $47.5 \%$ earned between 7,001 and 20,000 Baht/month, and approximately 10\% earned higher than that. Almost $50 \%$ reported having completed junior/high school before entering Open University. Forty percent had household assets estimated at less than 30,000 Baht and 28.7\% had household assets higher than 60,000 Baht. Close to half of the cohort members $(46.1 \%)$ lived in rural areas, $17.2 \%$ lived in Bangkok, and $36.7 \%$ lived in other urban areas. 
Table 1 Descriptive data of the cohort members, 'life satisfaction as a whole' and PWI scores

\begin{tabular}{|c|c|c|c|c|c|}
\hline \multirow{2}{*}{$\begin{array}{l}\text { Demographic, socioeconomic, } \\
\text { geographic characteristics } \\
\text { Overall }\end{array}$} & \multirow{2}{*}{$\begin{array}{l}\mathrm{N} \\
87,134\end{array}$} & \multirow{2}{*}{$\begin{array}{l}\% \\
100.0\end{array}$} & \multicolumn{2}{|c|}{ Satisfaction in 'Life as a Whole' } & \multirow{2}{*}{$\begin{array}{l}\text { PWI } \\
\text { score } \\
70.0\end{array}$} \\
\hline & & & $\begin{array}{l}\text { Mean } \\
75.7\end{array}$ & $\begin{array}{l}\text { SD } \\
\pm 17.3\end{array}$ & \\
\hline \multicolumn{6}{|l|}{ Sex } \\
\hline Male & 39,482 & 45.3 & 75.0 & \pm 17.7 & 70.4 \\
\hline Female & 47,642 & 54.7 & 76.3 & \pm 16.9 & 69.7 \\
\hline \multicolumn{6}{|l|}{ Age } \\
\hline $20-29$ & 44,207 & 50.7 & 74.4 & \pm 17.6 & 68.3 \\
\hline $30-39$ & 27,309 & 31.4 & 76.1 & \pm 17.0 & 70.9 \\
\hline $40-49$ & 10,948 & 12.6 & 78.8 & \pm 16.2 & 74.0 \\
\hline$\geq=50$ & 2,150 & 2.5 & 80.6 & \pm 15.8 & 75.9 \\
\hline \multicolumn{6}{|l|}{ Marital status } \\
\hline Married & 36,727 & 41.6 & 77.7 & \pm 16.1 & 72.1 \\
\hline Single & 47,843 & 54.2 & 74.2 & \pm 17.9 & 68.5 \\
\hline Separated/divorced/widowed & 3,648 & 4.1 & 72.2 & \pm 19.4 & 68.1 \\
\hline \multicolumn{6}{|l|}{ Income/month (Baht) } \\
\hline$<7,000$ & 35,632 & 41.9 & 73.8 & \pm 18.8 & 67.8 \\
\hline $7,001-10,000$ & 19,796 & 23.3 & 75.6 & \pm 16.4 & 70.0 \\
\hline $10,001-20,000$ & 20,564 & 24.2 & 77.5 & \pm 15.4 & 72.2 \\
\hline $20,001+$ & 8,952 & 10.5 & 79.6 & \pm 14.3 & 74.0 \\
\hline \multicolumn{6}{|l|}{ Education } \\
\hline Junior/high school & 42,448 & 48.9 & 74.9 & \pm 18.4 & 68.7 \\
\hline Diploma & 23,462 & 27.0 & 76.2 & \pm 16.5 & 70.5 \\
\hline Bachelor degree/above & 20,981 & 24.2 & 76.7 & \pm 15.6 & 71.5 \\
\hline \multicolumn{6}{|l|}{ Household assets } \\
\hline Low $(0-30,000$ Baht $)$ & 35,182 & 40.6 & 73.9 & \pm 18.2 & 69.5 \\
\hline Medium $(30,001-60,000$ Baht $)$ & 26,596 & 30.7 & 76.3 & \pm 16.7 & 70.1 \\
\hline High $(60,001+$ Baht $)$ & 24,903 & 28.7 & 77.7 & \pm 16.3 & 71.0 \\
\hline \multicolumn{6}{|l|}{ Residence } \\
\hline Bangkok & 14,862 & 17.2 & 73.8 & \pm 17.6 & 67.5 \\
\hline Urban not Bangkok & 31,775 & 36.7 & 75.5 & \pm 17.2 & 69.6 \\
\hline Rural & 39,957 & 46.1 & 76.6 & \pm 17.2 & 71.3 \\
\hline
\end{tabular}

\subsection{Mean Scores of 'Satisfaction in Life as a Whole' by Cohort Characteristics}

Overall 'satisfaction in life as a whole' has a mean of 75.7. Life satisfaction was slightly higher in females (76.3) compared to males (75.0) and tended to increase with age, 74.4 in ages 20-29 compared to 80.6 in older than 50 years. Those who were married rated themselves higher (77.7) than those who were single (74.2) and those who were separated/ divorced/widowed (72.2). Reporting 'satisfaction in life as a whole' also improved with increasing income, 73.8 in lowest group compared to 79.6 in highest group. Higher marks were also found with higher education, 74.9 in those with junior/high school education compared to 76.7 in those who already had a bachelor degree or above. Higher household assets were also linked with higher scores (73.9 in the lowest group compared to 77.7 in the 
highest group). Rural residents had higher scores compared to urban areas and scores were lowest in Bangkok.

\subsection{Personal Wellbeing Scores by Cohort Characteristics}

As noted earlier, the PWI score is calculated from the mean of all the domain scores in aggregation. Overall the PWI score of cohort members was 70.0. For all demographic and socioeconomic groups in the cohort the PWI score was approximately 5 points less than for 'satisfaction in life as a whole'. PWI itself varied a little according to sociodemographic characteristics and was higher for males and those who were older, married, with higher incomes, higher education, higher assets, and residing in rural areas.

\subsection{Cohort's Characteristics and Personal Wellbeing Domains}

Among eight domains of personal wellbeing (Table 2), the highest mean scores were for 'spiritual and religion' (76.5) followed by 'personal relationships' (72.4) and 'health' (72.2). The lowest scores reported were for sense of 'achievement in life' (65.6), sense of 'sense of community' (65.8), and 'standard of living' (67.6).

\subsubsection{Sex and Personal Wellbeing Domains}

Across all domains, males reported higher scores except for standard of living, achievement in life and personal relationship. Domain scores for 'spirituality and religion' (76.8 in male and 76.3 in females) and 'achievement in life' (65.4 in male and 65.7 in female) differed only very slightly.

\subsubsection{Age and Personal Wellbeing Domains}

There is a positive trend between increasing age and increasing scores in all domains. Largest score differences between the youngest and oldest age groups could be noted for 'standard of living' (65.5 vs. 75.3), 'achievement in life' (62.6 vs. 75.0), and 'future security' (64.7 vs. 78.2). The smallest difference across age groups was noted in 'personal relationship', 72.3 in the youngest compared to 73.6 in the oldest age groups. Those aged over 50 also showed the highest score of 80.9 for 'spirituality and religion' domain.

\subsubsection{Marital Status and Personal Wellbeing Domains}

Those who were married have higher scores compared to other groups across all domains. The largest differences were found between those married and those who reported being separated, divorced, and widowed especially for 'standard of living', 70.2 compared to 64.3, as well as 'future security', 72.9 compared to 65.2.

\subsubsection{Income and Personal Wellbeing Domains}

Higher income showed a positive gradient with all domain scores. More than 10 point differences between the lowest and highest income groups could be found in 'standard of living', 'achievement in life', and 'future security'. Relatively smaller gaps were shown for ratings of 'personal health', 'personal relationship', and 'spirituality and religion'. 


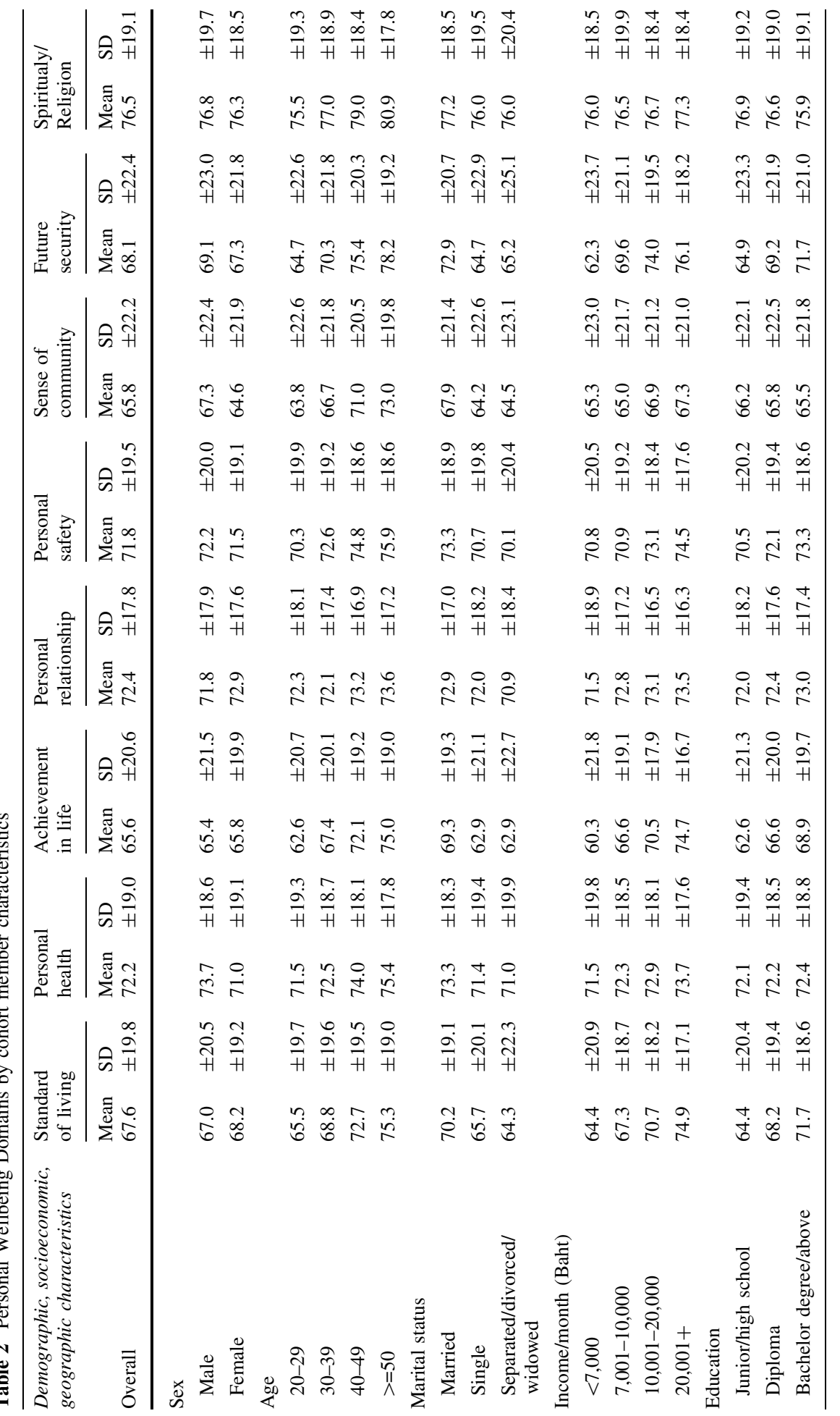




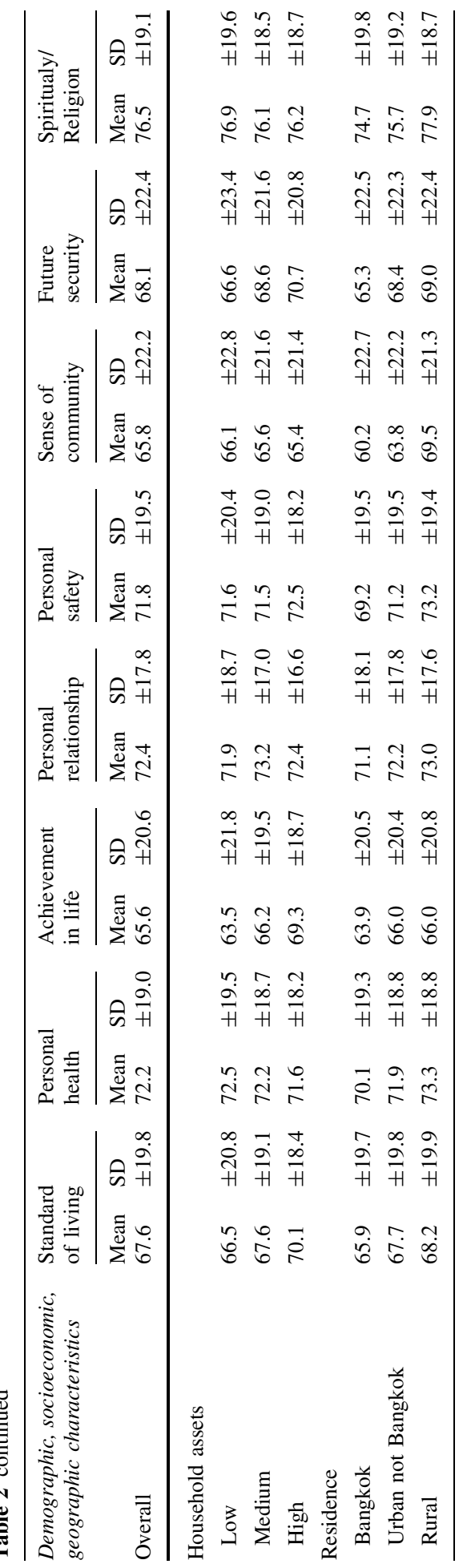




\subsubsection{Education and Personal Wellbeing Domains}

Similar to income, higher education levels could be associated with higher domain scores. The exceptions were scores for 'sense of community' ( 66.2 for junior/high school vs. 65.5 for bachelor degree or above) and 'spirituality and religion' (76.9 in lowest education group vs. 75.9 in highest education group).

\subsubsection{Household Assets and Personal Wellbeing Domains}

Similar to other socioeconomic indicators (income and education), household assets show a positive trend with higher score domains in 'standard of living', 'achievement in life' and 'future security'. However, a slight negative trend was found in 'personal health' (72.5 in the lowest group compared to 71.6 in the highest group) and 'sense of community' (66.1 compared to 65.4).

\subsubsection{Residence and Personal Wellbeing Domains}

Across all domains, rural residents reported higher scores than those in Bangkok and other urban areas. The biggest difference was in 'sense of community' with scores of 69.5 in rural and 63.8 in urban areas. Bangkok residents reported an average of 60.2, which is also the lowest score in all domains. Although Bangkok is much better-off socioeconomically than other areas, residents rated their 'standard of living', 'achievement in life', and 'future security' to be much lower than rural and other urban residents.

5.5 Domain Inter-Correlations, Correlation and Multiple Regression of 'Satisfaction with Life as a Whole' on PWI Domains

\subsubsection{Domain Inter-Correlations}

Table 3 shows correlations between domains. The highest correlation 0.70 was between 'achievement in life' and 'future security' followed by 0.64 between 'achievement in life'

Table 3 Domains inter-item correlations

\begin{tabular}{|c|c|c|c|c|c|c|c|c|}
\hline Domains & $\begin{array}{l}\text { Standard } \\
\text { of living }\end{array}$ & Health & $\begin{array}{l}\text { Achievement } \\
\text { in life }\end{array}$ & $\begin{array}{l}\text { Personal } \\
\text { relationship }\end{array}$ & $\begin{array}{l}\text { Personal } \\
\text { safety }\end{array}$ & $\begin{array}{l}\text { Sense of } \\
\text { community }\end{array}$ & $\begin{array}{l}\text { Future } \\
\text { security }\end{array}$ & $\begin{array}{l}\text { Spiritual/ } \\
\text { religion }\end{array}$ \\
\hline $\begin{array}{l}\text { Standard of } \\
\text { living }\end{array}$ & 1.00 & & & & & & & \\
\hline Personal health & 0.51 & 1.00 & & & & & & \\
\hline $\begin{array}{l}\text { Achievement in } \\
\text { life }\end{array}$ & 0.64 & 0.47 & 1.00 & & & & & \\
\hline $\begin{array}{l}\text { Personal } \\
\text { relationship }\end{array}$ & 0.45 & 0.44 & 0.48 & 1.00 & & & & \\
\hline Personal safety & 0.47 & 0.44 & 0.43 & 0.52 & 1.00 & & & \\
\hline $\begin{array}{l}\text { Sense of } \\
\text { community }\end{array}$ & 0.43 & 0.38 & 0.42 & 0.51 & 0.52 & 1.00 & & \\
\hline Future security & 0.59 & 0.43 & 0.70 & 0.44 & 0.49 & 0.49 & 1.00 & \\
\hline $\begin{array}{l}\text { Spirituality/ } \\
\text { religion }\end{array}$ & 0.38 & 0.35 & 0.34 & 0.39 & 0.38 & 0.42 & 0.36 & 1.00 \\
\hline
\end{tabular}


Table 4 Correlation and regression of 'satisfaction in life as a whole' on PWI domains

\begin{tabular}{llll}
\hline PWI domains & $\begin{array}{l}\text { Correlation with } \\
\text { 'life as a whole' }\end{array}$ & \multicolumn{2}{l}{ Regression: 'life as a whole' as dependent variable } \\
\cline { 3 - 4 } & & & Coefficient \\
\hline Life satisfaction & 1.00 & 0.196 & 0.000 \\
Standard of living & 0.65 & 0.079 & 0.000 \\
Personal health & 0.51 & 0.152 & 0.000 \\
Achievement in life & 0.65 & 0.084 & 0.000 \\
Personal relationship & 0.52 & 0.058 & 0.000 \\
Personal safety & 0.51 & 0.015 & 0.000 \\
Sense of community & 0.48 & 0.171 & 0.000 \\
Future security & 0.66 & 0.146 & 0.000 \\
Spirituality and religion & 0.49 & 0.619 & \\
$R^{2}$ & & 0.619 & \\
Adjusted $R^{2}$ & & &
\end{tabular}

and 'standard of living' Lowest correlations 0.34 were found between 'achievement in life' and 'spirituality and religion'.

\subsubsection{Bivariate Correlation of Personal Wellbeing Domains to 'Life as a Whole'}

Table 4 shows correlation results with the general item 'overall life satisfaction'. The correlations ranged from 0.48 to 0.66 . The highest correlations were found with 'future security' (0.66), 'standard of living' (0.65), 'achievement in life' (0.65). The lowest correlation was found $(0.48)$ in the domain of 'sense of community'.

\subsubsection{Multiple Regressions of Personal Wellbeing Domains against 'Life as a Whole'}

To determine the contribution of PWI domains to 'satisfaction in life as a whole', the latter was regressed on the domain items. Multiple regression results show 'overall life satisfaction' can be explained most by 'standard of living' $(\beta=0.196)$ followed by 'future security' $(\beta=0.171)$ and 'achievement in life' $(\beta=0.152)$. The lowest contributions were from 'sense of community' $(\beta=0.015)$ and 'personal safety' $(\beta=0.058)$. Results show that eight domains predicted $61.9 \%$ (Adjusted $R^{2}$ ) of 'satisfaction in life as a whole'.

\section{Discussion}

The personal wellbeing and domain scores reported in Tables 1 and 2 showed that, cohort members were satisfied with their lives with most respondents' scores ranging from 65 to 75. The 'satisfaction in life as a whole' was 75.7 while the PWI score was 70.0 . The PWI range for Western means is 70-80 points (Cummins et al. 2003; Renn et al. 2009) The PWI in Hong Kong and China were 10 points less (Chen and Davey 2008; Lau et al. 2005); however, PWI in Thailand we found to be very close to that of Tibetans and most Westerners (Webb 2008). Increasing age, being married, higher income, education, assets and being in rural areas were associated with higher scores for 'satisfaction with life as a 
whole' and PWI compared to other characteristics. The link between increased age, being married and higher PWI was found to be consistent with other studies (Smyth et al. 2009).

Some marked gradients of 10 point difference for 'standard of living', 'achievement in life', and 'future security' between the highest and lowest groups could be found across socioeconomic indicators (income, education, assets). Although 'personal relationship' scores were higher than 70 across all characteristics, there was a noted difference on 'sense of community' between rural, urban and Bangkok. Across all the domains, in our large Thai sample 'spirituality and religion' had the highest mean of 76.5 across the board and only showed slight differences between demographic, socioeconomic, and geographic characteristics. This 'spirituality and religion' domain was the latest to be introduced and although it has not been shown to be important in developed countries, it was important in Colombia (Wills 2009) and in a small sample of Buddhists from Tibet (Webb 2008).

The eight domains of the PWI's correlation with the general item of 'life as a whole' ranged from 0.34 to 0.70 . This result is similar to those found in Australia and Hong Kong (Lau et al. 2005). The highest correlations were found between 'achievement in life' and 'future security' followed by 'achievement in life' and 'standard of living'. Three domains, namely 'standard of living', 'achievement in life', and 'future security' were the most important in explaining 'life satisfaction as a whole'. Previous studies have also found 'standard of living' and 'life achievement' to be strong contributors. The two domains that least explained 'life satisfaction as a whole' were 'sense of community' and 'personal safety'. This is also true for Australia (Lau et al. 2005), Algeria (Tiliouine et al. 2006) and Hong Kong (Lau et al. 2005).

The domain of 'health' was not a strong contributor to 'satisfaction in life as a whole' in Thailand. This might be explained by the relative youthfulness of our cohort $(82 \%$ aged between 20 and 39 years) and by the universal health coverage scheme which was introduced in Thailand since 2001. The scheme covers costs of both curative and preventive care, including ambulatory and hospitalization services. This universal health coverage scheme has been shown to reduce the out-of-pocket payments, especially catastrophic health payments, and the health-related impoverishment of lower income households (Limwattananon et al. 2007; Vasavid et al. 2005).

In Thailand, the 'spirituality and religion' domain was shown to be a quite important for 'life as a whole'. The relationship between culture, spirituality and religion are intertwined and could also be beneficial to health and overall life satisfaction (Eckersley 2007; Williams and Sternthal 2007). The strength of Buddhism might provide a strong basis for explaining life satisfaction. Temples are an emergency source of food and shelter for some villagers as well as source of support for their stress (Paitoonpong et al. 2008). It is interesting to note in our results that having higher education or assets corresponded with lower scores in the 'sense of community' and 'spirituality and religion' domains, although these differences were rather small. 'Sense of community' was the smallest contributor to 'satisfaction in life as whole', and scored lower in Bangkok and urban areas. This might be explained by alienation and loss of community contacts associated with rapid urbanisation in Thailand which has affected a large proportion of our cohort (Lim et al. 2009).

\section{Conclusion}

The results from the current study provide further supportive evidence in the Thai context which has implications for the cross-cultural measurement of subjective wellbeing in developing countries. Most studies have found that 'standard of living' and 'achievement 
in life' make the largest contribution to 'satisfaction in life as a whole', consistent with the results reported here. In the Thai context, 'spirituality and religion' gained the highest mean score across all domains. The result here confirms that an additional domain of 'spirituality and religion' would be useful in subsequent studies. It also supports the Thai emphasis on balanced and integrated development as shown in the 'Green and Happiness Index' referred to in the conceptual framework section above.

In order to understand the wellbeing of population subgroups, PWI should be measured with respect to demographic, socioeconomic and geographic characteristics of population. Policy attention may be drawn to those with younger age, not-married, and of lower socioeconomic status who reported lower PWI and domain scores. An advantage of this cohort dataset is the ability to follow the cohort members and reevaluate their wellbeing over time especially as set out in the Thai national economic and social development goal. As Thailand is undergoing an economic and health transition and has adopted holistic development goals inspired by its Buddhist heritage, PWI will be an important tool to help policymakers understand the subjective wellbeing of the population.

\section{Appendix: Translation of PWI and Domain Items}

\section{Part 1: Life Satisfaction Overall}

Thinking about your own life and personal circumstances, how satisfied are you with your life as a whole?

เมื่อคิดถึงชีวิตของท่านและสภาพแวดล้อมของท่าน ท่านมีความพอใจ กับชีวิตโดยรวมของท่าน ในระดับใด

\section{Part 2: Domain Life Satisfaction}

1. "How satisfied are you with your standard of living?" มาตรฐานการดำรงชีวิต

2. "How satisfied are you with your health?" สุขภาพของท่าน

3. "How satisfied are you with what you are achieving in life?" ความสำเร็จในชีวิตของท่าน

4. "How satisfied are you with your personal relationships?" ความสัมพันธ์กับผู้อื่น

5. "How satisfied are you with how safe you feel?" ความรู้สึกปลอดภัย

6. "How satisfied are you with feeling part of your community?" ความรู้สึกเป็นส่วนหนึ่งของชุมชนที่ท่านอยู่

7. "How satisfied are you with your future security?" ความมั่นคงในอนาคต

8. "How satisfied are you with your religion or spirituality?" ศาสนาหรือด้านจิตวิญญาณของท่าน

\section{References}

Chen, Z., \& Davey, G. (2008). Happiness and subjective well-being in Mainland China. Journal of Happiness Studies, 9, 589-600.

Cohen, A. B. (2002). The importance of spiritual in well-being for Jews and Christians. Journal of Happiness Studies, 3, 287-310.

Cummins, R. A. (2000). Personal income and subjective well-being: A review. Journal of Happiness Studies, 1, 133-158. 
Cummins, R. A., Eckersley, R., Pallant, J., van Vugt, J., \& Misajon, R. (2003). Developing a national index of subjective wellbeing. The Australian Unity Wellbeing Index. Social Indicators Research, 64, 159-190.

Diener, E. (1984). Subjective well-being. Psychological Bulletin, 95(3), 542-575.

Diener, E. (2000). Subjective well-being. The science of happiness and a proposal for a national index. American Psychologist, 55(1), 34-43.

Diener, E., Emmons, R. A., Larsen, R. J., \& Griffin, S. (1985). The satisfaction with life scale. Journal of Personality Assessment, 49(1), 71-75.

Easterlin, R. A. (2003). Explaining happiness. The Proceedings of the National Academy of Sciences Online (US), 100(19), 11176-11183.

Eckersley, R. (2002). Health, wellbeing and progress. The New South Wales Public Health Bulletin, 13(6), $128-130$.

Eckersley, R. M. (2007). Culture, spirituality, religion and health: Looking at the big picture. The Medical Journal of Australia, 186(10 Suppl), S54-S56.

Khamman, S. (2008). Social capital and human capital development. Paper presented at the 2008 year-end conference on sustaining long-term growth, Chonburi, Thailand.

Krongkaew, M. (1993). Poverty and income distribution. In P. G. Warr (Ed.), The Thai economy in transition. Cambridge: Cambridge University Press.

Lau, A., Cummins, R. A., \& Mcpherson, W. (2005). An investigation into the cross-cultural equivalence of the Personal Wellbeing Index. Social Indicators Research, 72, 403-430.

Lim, L., Kjellstrom, Y., Sleigh, A., Khamman, S., Seubsman, S., Dixon, J., \& Banwell, C. (2009). Associations between urbanisation and components of the health-risk transition in Thailand. A descriptive study of 87,000 Thai adults. Global Health Action. DOI: 10.3402/gha.v52i0.1914.

Limwattananon, S., Tangcharoensathien, V., \& Prakongsai, P. (2007). Catastrophic and poverty impacts of health payments: Results from national household surveys in Thailand. Bulletin of the World Health Organization, 85(8), 600-606.

NESDB. (2005). Concept and strategies for national development during the 10th national development plan. Bangkok: National Economic and Social Development Board.

NESDB. (2007). Green and happiness index of Thailand. Bangkok: National Economic and Social Development Board.

NSO. (2006). Key statistics of Thailand 2006. Bangkok: National Statistical Office.

O'Dea, I., Hunter, M. S., \& Anjos, S. (1999). Life satisfaction and health-related quality of life (SF-36) of middle-aged men and women. Climacteric, 2(2), 131-140.

Paitoonpong, S., Shigeyuki, A., \& Puopongsakorn, N. (2008). The meaning of "social safety nets". Journal of Asian Economics, 19, 467-473.

Renn, D., Pfaffenberger, N., Platter, M., Mitmansgruber, H., Cummins, R. A., \& Hofer, S. (2009). International well-being index: The Austrian version. Social Indicators Research, 90, 243-256.

Sarntisart, I. (2004). Growth, structural change, and inequality: the experience of Thailand. In G. A. Cornia (Ed.), Inequality, growth, and poverty in an era of liberalization and globalization. Oxford: Oxford University Press.

Sen, A. (1988). The concept of development. In H. B. Chenery \& T. N. Srinivasan (Eds.), Handbook of development economics. Amsterdam: North-Holland.

Sen, A. K. (1999). Development as freedom. New York: Knopf.

Seubsman, S., Prapamontol, T., Khamman, S., Somboonsuk, B., Kamolsukudom, N., \& Vilanerun, D. (2007). Look back study on the Thai health-risk transition. Nonthaburi: Sukhothai Thammathirat Open University Press.

Siahpush, M., Spittal, M., \& Singh, G. K. (2008). Happiness and life satisfaction prospectively predict selfrated health, physical health, and the presence of limiting, long-term health conditions. American Journal of Health Promotion, 23(1), 18-26.

Sleigh, A. C., Seubsman, S. A., \& Bain, C. (2008). Cohort profile: The Thai Cohort of 87, 134 Open University students. International Journal of Epidemiology, 37(2), 266-272.

Smyth, R., Nielsen, I., \& Zhai, Q. (2009). Personal well-being in urban China. Social Indicators Research. doi:10.1007/s11205-009-9457-2.

Stevenson, B., \& Wolfers, J. (2008). Economic growth and subjective well-being: reassessing the easterlin paradox: Brookings Papers on Economic Activity. Retrieved September 30, 2009, from http://bpp.wharton.upenn.edu/betseys/papers/Happiness.pdf.

Tangcharoensathien, V., \& Jongudomsuk, P. (2004). From policy to implementation: historical events during 2001-2004 of universal coverage in Thailand. Nonthaburi: National Health Security Office.

The International Wellbeing Group. (2006). Personal Wellbeing Index-Adult (Manual 4th ed.) Melbourne: Australian Centre on Quality of Life, Deakin University. 
Tiliouine, H., Cummins, R. A., \& Davern, M. (2006). Measuring wellbeing in developing countries: The case of Algeria. Social Indicators Research, 75, 1-30.

UNDP. (2005). Human development report 2005. New York: Human Development Report Office.

Vasavid, C., Tisayaticom, K., Patcharanarumol, W., Tangcharoensathien, V., \& Lertpatraphong, K. (2005). Health and welfare of Thai population after Universal Care Coverage (UC) - Part II: Household health expenditure before and after UC. Journal Health Science [in Thai], 14(2), 317-325.

Veenhoven, R. (2002). Why social policy needs subjective indicators. Journal of Happiness Studies, 58, 3346.

Warr, P. G. (2004). Globalization, growth, and poverty reduction in Thailand. ASEAN Economic Bulletin, $21(1), 2-18$.

Wasi, P. (2004, September). Gross National Happiness Index in the Asia Context: The Message from Bhutan. Paper presented at the Gross National Happiness Conference at the Asian Institute of Technology, Bangkok, Thailand.

Webb, D. (2008). Subjective wellbeing on the Tibetan plateau: An exploratory investigation. Journal of the Happiness Studies. doi: 10.1007/s10902-10008-19120-10907.

WHO. (2004). The World Health Report 2004: Changing history. Geneva: World Health Organization.

Wibulpolprasert, S., Tangcharoensathien, V., \& Kanchanachitra, C. (2008). Three decades of primary health care: Reviewing the past and defining the future. Bulletin of the World Health Organization, 86(1), 3.

Williams, D. R., \& Sternthal, M. J. (2007). Spirituality, religion and health: Evidence and research directions. The Medical Journal of Australia, 186(10 Suppl), S47-S50.

Wills, E. (2009). Spirituality and subjective well-being: Evidences for a new domain in the personal wellbeing index. Journal of the Happiness Studies, 10, 49-69.

World Bank. (2000). Thailand social monitor: Social capital and crisis. Bangkok: The World Bank. 